\title{
Thermal stability of Ti-45Nb mechanically alloyed powder
}

\author{
Zh. G. Kovalevskaya ${ }^{1,2}$, Yu. P. Sharkeev ${ }^{1,2}$, M. A. Khimich ${ }^{1,3, \dagger}$, I. A. Glukhov ${ }^{1}$ \\ †khimich@ispms.tsc.ru
}

\author{
${ }^{1}$ Institute of Strength Physics and Materials Sciences, SB RAS, 2/4 Akademicheskii ave., Tomsk, 634055, Russia \\ ${ }^{2}$ National Research Tomsk Polytechnic University, 30 Lenin ave., Tomsk, 634050, Russia \\ ${ }^{3}$ National Research Tomsk State University, 36 Lenin ave., Tomsk, 634050, Russia
}

\begin{abstract}
The thermal stability of $\mathrm{Ti}-45 \mathrm{Nb}$ powder obtained via mechanical alloying of pure components $\mathrm{Ti}$ and $\mathrm{Nb}$ using an AGO-2C high energy planetary ball mill was studied. To evaluate the structure and phase transformations in the material, scanning and transmission electron microscopic studies and $\mathrm{x}$-ray diffraction analysis were carried out. Mechanical alloying of titanium and niobium powders occurs under the conditions of severe plastic deformation and leads to the homogenization of initial components. As a result, an alloy with the structure consisting of a mixture of different grains is formed. This mixture of nanosized grains consists of the main $\beta$-TiNb phase and metastable $\alpha$ - and $\alpha^{\prime \prime}$-phases. The presence of metastable phases, large amount of interfaces, lattice distortions of the main phase indicate the presence of high internal energy stored in the material. By means of differential scanning calorimetric analysis it was found that structural and phase transformations occurred during heating of the powder up to temperatures of about $500^{\circ} \mathrm{C}$ and $700^{\circ} \mathrm{C}$. During annealing at $500^{\circ} \mathrm{C}$ the mechanically alloyed powder loses the metastable $\alpha^{\prime \prime}$-phase while the $\alpha$-phase becomes equilibrium. At the same time, the process of recrystallization nuclei formation starts in the structure. The annealing at $700^{\circ} \mathrm{C}$ does not change the phase composition of the alloy. The exothermal effect observed at this temperature is related to structural transformations in the alloy, in other words, to the recrystallization of plastically deformed material. Basing on the results obtained it was concluded, that the upper limit of the thermal stability of mechanically alloyed $\mathrm{Ti}-45 \mathrm{Nb}$ powder does not exceed $500^{\circ} \mathrm{C}$.
\end{abstract}

Keywords: mechanical alloying, AGO-2C ball mill, Ti-45Nb powder, thermal stability, annealing.

\section{Introduction}

The methods of severe plastic deformation (SPD) find a wide application in the production of medical implants [1]. The basis for this is the formation of nanosized and submicrocrystalline structures in the material under SPD conditions. Such structures provide not only increased mechanical properties, but also a higher biocompatibility of the implants and bone tissue [ $1-3]$. Ingots of bioinert lowmodulus alloys produced via arc melting are used as initial materials for SPD $[4,5]$. It is highly desirable, however, to replace this technological procedure with the one consuming less energy. For this goal, the method of mechanical alloying of pure components in a ball mill can be used [6]. The particles of the initial components interact with each other and with the mill elements inside a high energy ball mill that leads to heating, SPD of the initial particles, their milling and refining, mixing and chemical compounding. As a result, particles of a new alloy with a nanosized structure are formed.

The method of mechanical alloying allows producing a wide range of titanium-based materials used in biomedicine. Among these, alloys of the $\mathrm{Ti}-\mathrm{Nb}$ system are promising materials. They have a low elastic modulus comparable to that of a bone tissue in the $\mathrm{Nb}$ concentration range of $40-45$ wt. \% [7]. At present, a study on the feasibility of the structure formation and properties of mechanically alloyed $\mathrm{Ti}-\mathrm{Nb}$ alloys is ongoing and the possible application areas are explored $[8,9]$. The phase composition and structure of the produced materials are described. The influence of the mechanical alloying modes, such as the time of high-energy mechanical treatment on the structure of the alloys is defined [8-12].

At the same time, the upper limit of the thermal stability of the produced material still remains unexplored, while this issue is very important for an evaluation of the behavior of material during its further compacting. This paper is aimed at a study on the thermal stability of the mechanically alloyed $\mathrm{Ti}-45 \mathrm{Nb}$ alloy powders.

\section{Methodology}

To produce the alloy, powders of commercially pure PTM grade titanium and NBP-a grade niobium have been used. The components were mixed in a ratio of $55 \mathrm{wt}$. \% titanium and 45 wt. $\%$ niobium (Ti-45Nb).

The mechanical alloying was carried out in a watercooled AGO-2C planetary ball mill [10]. The mixtures of initial powders were loaded by 10 grams each into the of 135 $\mathrm{ml}$ vials along with the grinding balls $5-6 \mathrm{~mm}$ in diameter made of instrumental hardened steel having the total mass of $164 \mathrm{~g}$. The centrifugal acceleration of the balls reached $400 \mathrm{~m} / \mathrm{s}^{2}$, the duration of treatment amounted 15 minutes [10]. Annealing of the mechanically alloyed powder was carried out in 1 hour in a high-vacuum oven at temperatures of $500^{\circ} \mathrm{C}$ and $700^{\circ} \mathrm{C}$. 
To evaluate the phase and physico-chemical transformations observed in the powder during a heating process, results of differential scanning calorimetric (DSC) analysis performed at STA 409 PC Luxx installation were used. The test specimens were put into the platinum crucible and were heated in the $25-1000^{\circ} \mathrm{C}$ temperature range at the rate of $10 \mathrm{~K} / \mathrm{min}$ in the presence of argon inert atmosphere.

The morphology of produced powders was studied using LEO EVO 50 scanning electron microscope. The thin structure of powders was studied by transmission electron microscopy (TEM) on a JEOL JEM-2100 microscope in the light and dark fields with an evaluation of the elemental composition made simultaneously with the use of energydispersive analyzer. X-ray diffraction analysis (XRD) was carried out on a DRON-7 diffractometer in monochromatic $\mathrm{CoK}_{\alpha}$-radiation according to the Bragg-Brentano scheme. The phase composition was identified with the PDF4+ database of "The International Centre for Diffraction Data" (ICDD). The reflexes from different phases were separated with the method of Fourier analysis, which allowed one to calculate such structural parameters as volume fractions of phases $(S)$ [13], lattice parameters $(a, c)$, cell volume $(V)$ and the sizes of coherently scattering regions (CSR).

\section{Results and discussion}

A powder alloy is formed when the two pure components, titanium and niobium powders, are mechanically alloyed. An analysis of the elemental composition of the powder shows that titanium and niobium are uniformly distributed throughout the material. The powder particles have a pellet shape with the average size of $25 \pm 2 \mu \mathrm{m}$ (Fig. 1a).

According to the XRD data, the weight fraction of the main phases is changed in the alloy (Table 1 ). The $\beta$-phase (bcc niobium based solid solution of 229 space group) fraction increases from $45 \pm 0.5$ to $77 \pm 0.5$ vol. \%. The $\alpha$-phase (hcp titanium based solid solution of 194 space group) fraction decreases from $55 \pm 0.5$ to $23 \pm 0.5$ vol. \%. The cell volumes of both phases decrease (see Table 1). Such a behavior is typical for mutual solid solutions of titanium and niobium. The $\alpha$-phase cell volume decreases after mechanical alloying from $0.0361 \pm 0.0003$ to $0.0341 \pm 0.0003 \mathrm{~nm}^{3}$. This is significantly less than the $\alpha$-Ti cell volume $\left(0.0351 \mathrm{~nm}^{3}\right)$ with the niobium maximum solubility in $\alpha$-Ti of $5 \%$. It follows that in the process of mechanical alloying the supersaturated $\alpha$-Ti solid solution with more than $5 \%$ dissolved niobium is formed in the material. Decrease of the $\beta$-phase lattice parameter listed in the table is caused by the dissolution of $18 \%$ titanium in niobium [14]. Since the concentration of titanium in the $\beta$-phase in an equilibrium state can exceed $50 \mathrm{wt} \%$, the produced $\beta$-TiNb solid solution can be considered to be in equilibrium.

As the calculated values of the CSR size in both phases show (Table 1), in the process of mechanical alloying, a refinement of structural elements of the $\beta$ - and $\alpha$-phases occurs. According to TEM data, a nanocrystalline structure is formed in the material in the process of mechanical alloying (Fig. 2). This is confirmed by light and dark field images and the microdiffraction patterns. Individual particles of the powder consist of many fine crystallites with different orientations. For example, 10-70 nm sized grains are

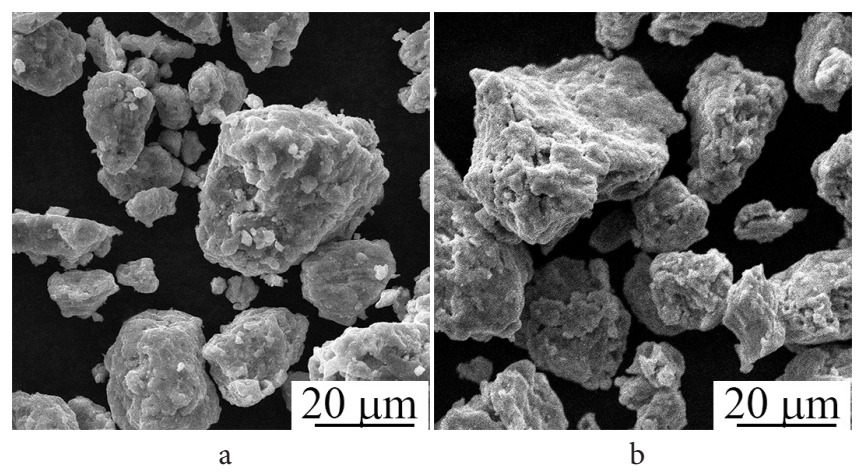

Fig. 1. SEM-image of the powder particles after mechanical alloying (a) and annealing at $700^{\circ} \mathrm{C}(\mathrm{b})$.

Table 1. The parameters of the phases in mechanically alloyed powder Ti-45Nb.

\begin{tabular}{|c|c|c|c|c|c|c|}
\hline \multirow{2}{*}{ Phase } & \multirow{2}{*}{ Parameters } & \multicolumn{2}{|c|}{ Powder } & \multirow{2}{*}{ Alloy } & \multicolumn{2}{|c|}{ Annealed alloy } \\
\hline & & $\mathrm{Ti}$ & $\mathrm{Nb}$ & & $500^{\circ} \mathrm{C}$ & $700^{\circ} \mathrm{C}$ \\
\hline \multirow{4}{*}{$\beta$} & $S$, vol. \% & - & $45 \pm 0.5$ & $77 \pm 0.5$ & $75 \pm 0.5$ & $73 \pm 0.5$ \\
\hline & $a, \mathrm{~nm}$ & - & $\begin{array}{c}0.3306 \pm 0.0002 \\
\left(0.3303^{*}\right)\end{array}$ & $0.3290 \pm 0.0002$ & $0.3291 \pm 0.0002$ & $0.3289 \pm 0.0002$ \\
\hline & $V, \mathrm{~nm}^{3}$ & - & $0.0361 \pm 0.0003$ & $0.0356 \pm 0.0003$ & $0.0356 \pm 0.0003$ & $0.0356 \pm 0.0003$ \\
\hline & $C S R, \mathrm{~nm}$ & - & $34 \pm 4$ & $132 \pm 4$ & $312 \pm 4$ & $515 \pm 4$ \\
\hline \multirow{5}{*}{$\alpha$} & S, vol. \% & $55 \pm 0.5$ & - & $23 \pm 0.5$ & $25 \pm 0.5$ & $27 \pm 0.5$ \\
\hline & $a, \mathrm{~nm}$ & $\begin{array}{c}0.2949 \pm 0.0002 \\
\left(0.2951^{*}\right)\end{array}$ & - & $0.2955 \pm 0.0002$ & $0.2969 \pm 0.0002$ & $0.2975 \pm 0.0002$ \\
\hline & $c, \mathrm{~nm}$ & $\begin{array}{c}0.4684 \pm 0.0002 \\
\left(0.4683^{*}\right)\end{array}$ & - & $0.4510 \pm 0.0002$ & $0.4741 \pm 0.0002$ & $0.4758 \pm 0.0002$ \\
\hline & $V, \mathrm{~nm}^{3}$ & $0.0361 \pm 0.0003$ & - & $0.0341 \pm 0.0003$ & $0.0362 \pm 0.0003$ & $0.0365 \pm 0.0003$ \\
\hline & $C S R, \mathrm{~nm}$ & $259 \pm 4$ & - & $143 \pm 4$ & $79 \pm 4$ & $429 \pm 4$ \\
\hline
\end{tabular}

"lattice parameters according to the ICDD PDF4+. 


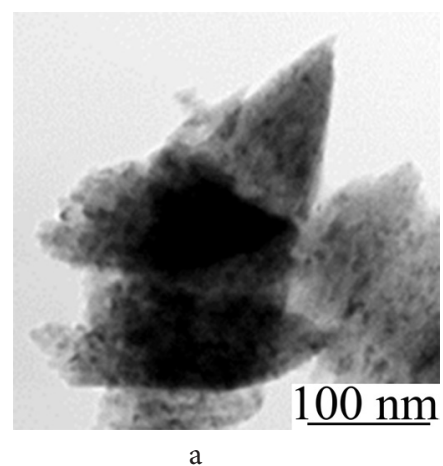

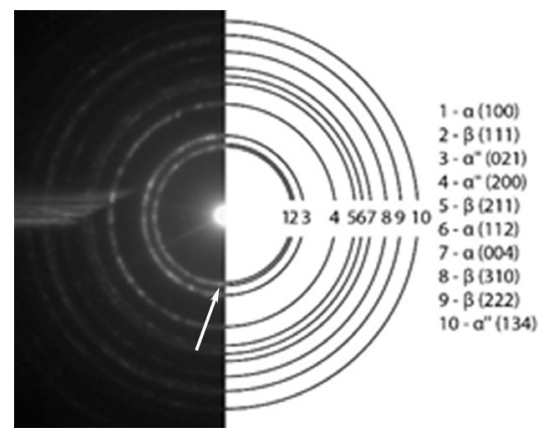

b

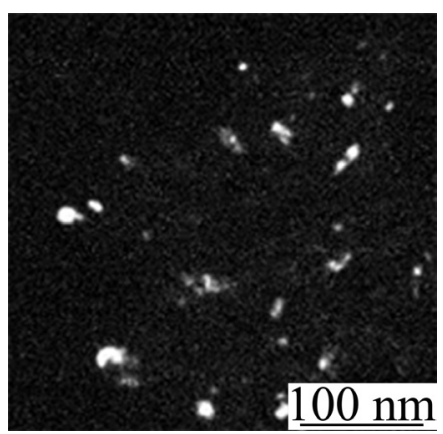

$\mathrm{c}$

Fig. 2. Alloyed powder TEM-image: light-field (a), microdiffraction pattern (arrow indicates the dark field reflex) (b), dark-field in $\beta(111)$ reflex (c).

observed on the dark-field image in $\beta$ (111) reflex (Fig. 2c). Microdiffraction patterns of all phases have a quasi-ring shape with an azimuthal broadening of the most reflexes (Fig. 2b). The quasi-ring shape indicates the significant refinement of the microstructural elements and the azimuthal broadening of the reflexes points at the high level of residual internal stresses.

An analysis of the microdiffraction patterns shows that the particles consist of $\beta$-, $\alpha$ - and $\alpha^{\prime \prime}$-phase grains (Fig. 2b). The $\alpha^{\prime \prime}$-phase, a metastable martensite with an orthorhombic lattice of 63 space group, is usually formed in the alloy during quenching [15]. Its formation is also possible in SPD conditions, when the processes of phase transformations resulting in the formation of metastable and nonequilibrium phases in titanium alloys are intensified [16]. The $\alpha^{\prime \prime}$-phase has been identified in the studied material only by means of TEM. This indicates the small amount of this phase in the alloy. The volume fraction of $\alpha$ "-phase is less than 3-5 vol. \% and is below the detection limit of the XRD method.

Thus, the $\mathrm{Ti}-45 \mathrm{Nb}$ alloy powder produced by mechanical alloying consists of a mixture of nanosized grains of $\beta$-TiNb, $\alpha$ - and $\alpha^{\prime \prime}$-phases and possesses a high level of stored internal energy.

To evaluate the influence of heating on the mechanically alloyed $\mathrm{Ti}-45 \mathrm{Nb}$ structure and phase composition, DSC scans have been carried out (Fig. 3). Two exothermal peaks are observed on the heating curve in the temperature range of $25-1000^{\circ} \mathrm{C}$. The first peak occurs in the temperature range of $450-500^{\circ} \mathrm{C}$ and the second one in the range $650-700^{\circ} \mathrm{C}$. No thermal effects have been observed on the cooling curve.

Exothermal effects during heating could be caused by the processes of structural relaxation and phase transformations. The processes of recovery, polygonization and recrystallization occur with a heat release [17]. Also, the process of a decomposition of the metastable $\alpha$ "-phase into equilibrium $\alpha$ - and $\beta$-phases is accompanied by an exothermal effect. The temperature ranges of the mentioned processes depend on the amount of niobium in the solid solution and are displaced to lower temperatures with its increase $[18,19]$.

The polymorphic transformation of the low-temperature $\alpha$-phase into the high-temperature $\beta$-phase is accompanied by heat absorption and is reversible. Since the thermal effects are not observed during the cooling of the alloy, the process of polymorphic transformation of titanium at chosen temperature range can be excluded.
To interpret the structural and phase transformations occurring in the alloy during heating process, the powder was annealed at $500^{\circ} \mathrm{C}$ and $700^{\circ} \mathrm{C}$ for 1 hour. It was found that the morphology and granular composition of the powder did not change after annealing (Fig. 1b). At the same time, after annealing at $500^{\circ} \mathrm{C}$ the change of the phase composition occurs. According to the XRD data, the $\alpha$-phase fraction increased by $2 \pm 0.5$ vol. \% (Table 1 ). TEM results have shown the presence of reflexes of only the $\alpha$ - and $\beta$-phases in the microdiffraction patterns. There are no reflexes of the $\alpha^{\prime \prime}$-phase. It can be concluded, therefore, that the decomposition of nonequilibrium $\alpha^{\prime \prime}$-phase into equilibrium ones occurs in the produced material at $500^{\circ} \mathrm{C}$.

Analysis of the elemental composition has shown that titanium and niobium are distributed less uniformly than in the initial state. The concentration of niobium in local areas changes from 57 to $92 \%$. This means that during heating the process of decomposition of supersaturated solid solutions is activated. According to XRD data, the $\alpha$-phase cell volume recovers its equilibrium value after annealing that indicates the precipitation of niobium from the supersaturated $\alpha$-solid solution. The value of the lattice parameter of $\beta$-phase does not change (Table 1).

Annealing at $500^{\circ} \mathrm{C}$ leads to an initialization of structural transformations. As one can see from the XRD pattern, the intensity of the peaks of the main phase increases after heating. This indicates that the processes of substructure transformation occur in the alloy (Figs. 4a, b).

This conclusion is confirmed by the TEM results. Fig. 5 shows that the material retains a nanocrystalline structure. Areas with the grain size less than $100 \mathrm{~nm}$ can be observed on the dark-field image in the $\beta(111)$ reflex (Fig. 5c). Microdiffraction patterns from individual regions show that in the material there are areas consisting of crystallites of the $\beta$-phase and mixture of the $\beta$ - and $\alpha$-phases (Figs. 5b, e).

During annealing nucleation centers of the $\beta$-phase are formed (Figs. 5d-5f). This means an initialization of the recrystallization process. The nucleation centers of the $\beta$-phase contain about $18 \mathrm{wt}$. \% titanium. This corresponds to the value of titanium concentration in the $\beta$-phase calculated from the XRD data.

Basing on the analysis carried out, one can conclude that on heating the powders of mechanically alloyed $\mathrm{Ti}-45 \mathrm{Nb}$ up to $500^{\circ} \mathrm{C}$ the decomposition of metastable phases occurs along with a simultaneous initialization of a 
structural transformation, which consists in the formation of recrystallization nuclei.

After annealing of the powder at $700^{\circ} \mathrm{C}$ the XRD studies show a significant increase of the intensity of the peaks from $\alpha$ - and $\beta$-phases (Fig. 4c). The widths of the peaks decrease, residual internal stresses relax and the crystallite sizes increase. According to the data calculated from XRD patterns, the sizes of CSR in both phases increase more than three times (Table 1). Due to heating up to $700^{\circ} \mathrm{C}$ the weight fraction of the $\alpha$-phase slightly increases without a significant change of the lattice parameters of $\alpha$ - and $\beta$-phases. One can assume that the second exothermal peak on the DSC heating curve is associated not with the phase transformations, but with the structural transformations caused by a recrystallization of the plastically deformed alloy. Additional studies are required to confirm this conclusion.

\section{Conclusions}

Basing on the studies carried out in the present work, one can conclude that during mechanical alloying of $\beta-\mathrm{Nb}$ and $\alpha-\mathrm{Ti}$ powders an alloy is formed with the structure consisting of a mixture of nanosized $\beta$-TiNb grains and metastable $\alpha$ - and $\alpha$ "-phases. The presence of nonequilibrium phases, a large number of interfaces, and lattice microdistortions of the main phase indicate the presence of internal energy stored in the material.

During annealing of the powder at $500^{\circ} \mathrm{C}$, decomposition of metastable phases occurs in the mechanically alloyed Ti-45Nb. The metastable $\alpha$ "-phase disappears, solid solution of niobium in the $\alpha$-phase becomes equilibrium. Substructure transformation starts in the alloy, which consists in the formation of recrystallization nuclei of the $\beta$-phase. All

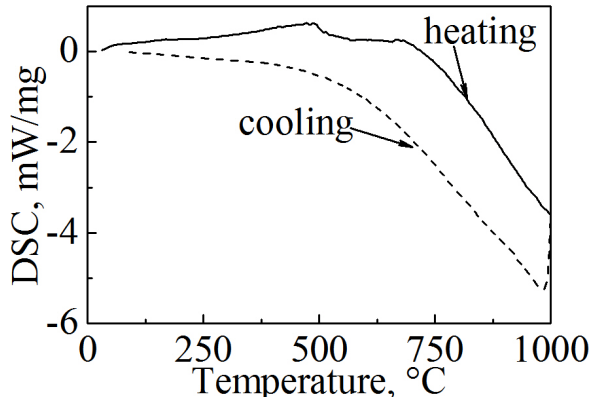

Fig. 3. Heating and cooling DSC curves of the alloyed powder.

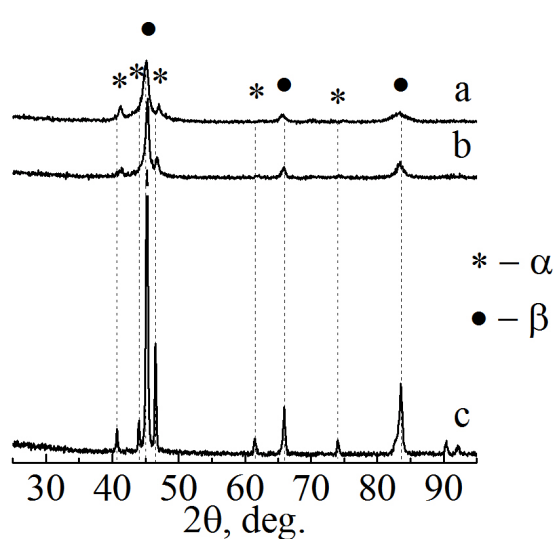

Fig. 4. X-ray diffraction pattern of the powder after alloying (a) and annealing at $500^{\circ} \mathrm{C} \mathrm{(b)}$ and $700^{\circ} \mathrm{C}(\mathrm{c})$.
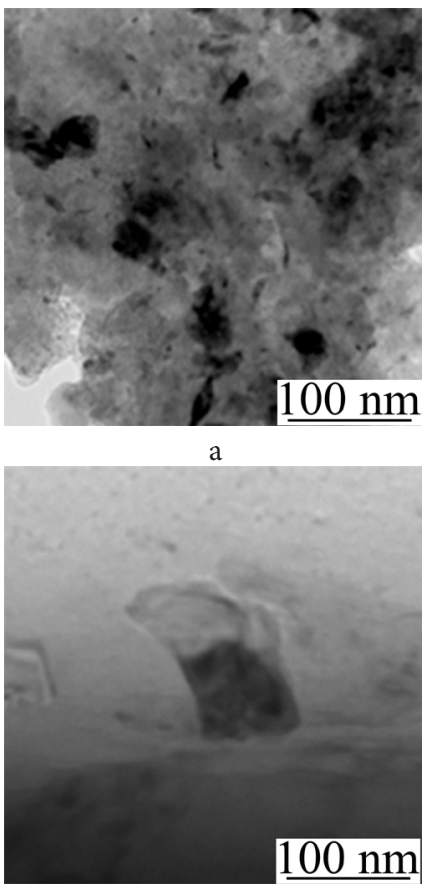
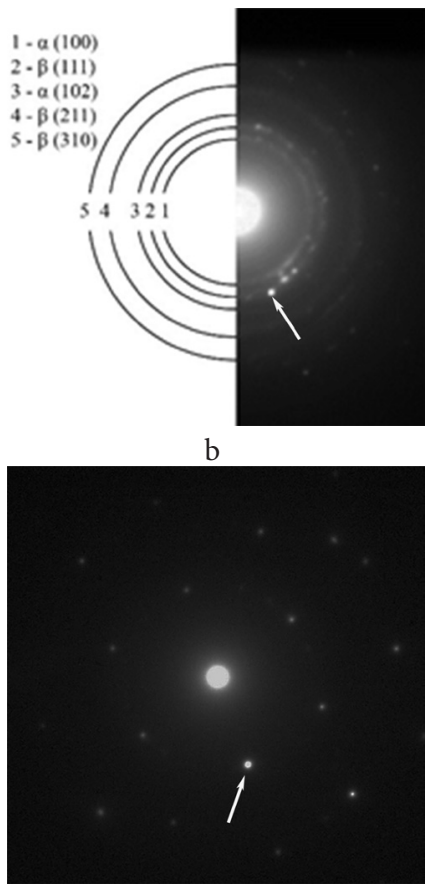
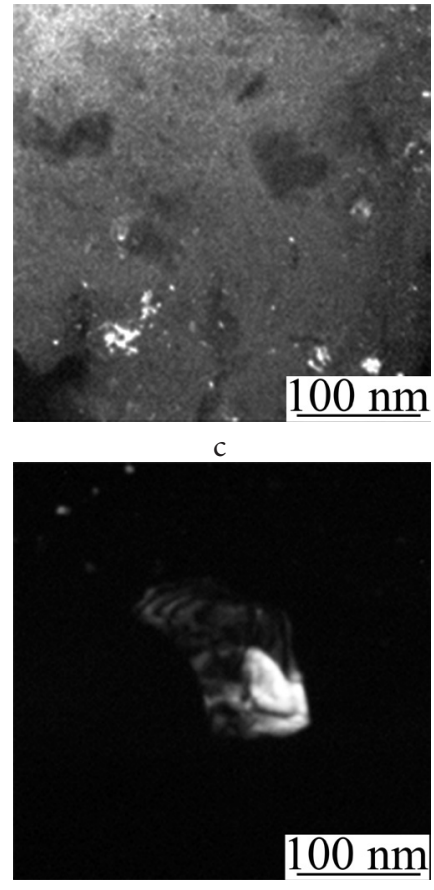

$\mathrm{f}$

Fig. 5. TEM-image of the alloyed powder after annealing at $500^{\circ} \mathrm{C}$ : light-field (a, d), microdiffraction patterns (arrows indicate the dark-field reflexes) (b,e), dark-field in $\beta$ (111) reflex (c), dark-field in $\beta(002)$ reflex (f). 
these structural and phase transformations occur with a heat release, which is detected as an exothermal peak on the heating curve obtained by means of the differential scanning calorimetry.

Annealing at $700^{\circ} \mathrm{C}$ does not significantly change the phase composition of the alloy. The exothermal peak, which is typical for this temperature, is associated with the structural transformations in the alloy, namely, with the recrystallization of the plastically deformed material.

Thus, the upper limit of the thermal stability of the mechanically alloyed $\mathrm{Ti}-45 \mathrm{Nb}$ alloy powder is limited to $500^{\circ} \mathrm{C}$.

Acknowledgments. This work was performed within the frame of the Fundamental Research Program of the State Academies of Sciences for 2013-2020, line of research III.23.2.2.

\section{References}

1. C.N. Elias, M.A. Meyers, R.Z. Valiev, S.N. Monteiro. J. Mater. Res. Technol. 2(4), 340 (2013). DOI:10.1016/j.jmrt.2013.07.003

2. S. Faghihi, A.P. Zhilyaev, J.A. Szpunar, F. Azari, H. Vali, M. Tabrizian. Adv. Mater. 19, 1069 (2007). DOI: 10.1002/adma.200602276

3. L. Saldana, A. Mendez-Vilas, L. Jiang, M. Multigner, J.L. Gonzalez-Carrasco, M.T. PerezPrado, M.L. Gonzalez-Martin, L. Munuera, N. Vilaboa. Biomater. 28(30), 4343 (2007). DOI: 10.1016/j.biomaterials.2007.06.015

4. J.M. Cordeiro, T. Beline, A.L. R. Ribeiro, E.C. Rangel, N. C. da Cruz, R. Landers, L.P. Faverani, L.G. Vaz, L. M. G. Fais, F. B. Vicente, C. R. Grandini, M. T. Mathew, C. Sukotjo, V.A. R. Barão. Dent. Mater. 33, 1244 (2017). DOI: 10.1016/j.dental.2017.07.013

5. Zh.G. Kovalevskaya, M.A. Khimich, A.V. Belyakov, I. A. Shulepov. Adv. Mater. Res. 1040, 39 (2014). DOI: 10.4028/www.scientific.net/AMR.1040.39

6. C. Suryanarayana. Progress in Mater. Sci. 46, 1 (2001).

7. T. Ozaki, H. Matsumoto, S. Watanabe, S. Hanada. Mater.
Trans. 45(8), 2776 (2004).

8. Yu. P. Sharkeev, A. Yu. Eroshenko, Zh. G. Kovalevskaya, A. A Saprykin, E.A. Ibragimov, I.A. Glukhov, M. A. Khimich, P. V. Uvarkin, E. V. Babakova. Russian Phys. J. 59(3), 430 (2016). DOI: 10.1007/s11182-016-0790-Z

9. K. Zhuravleva, S. Scudino, M.S. Khoshkhoo, A. Gebert, M. Calin, L. Schultz, J. Eckert. Adv. Eng. Mater. 15(4), 262 (2013). DOI: 10.1002/adem.201200117

10. Zh.G. Kovalevskaya, Y.P. Sharkeev, M.A. Khimich, M. A. Korchagin, V.A. Bataev. Nanosi. and Technol.: an Int. J. 8(3), 203 (2017). DOI: 10.1615/NanoSciTechnolIntJ. v8.i3.30

11. Y.A. Giffoni, E. C. T. Ramos, H.R. Z. Sandim, M.T. T. Pacheco, G. Silva, A.S. Ramos. Mater. Sci. Forum 591-593, 141 (2008). DOI: 10.4028/www.scientific.net/MSF.591-593.141

12. K. Zhuravleva, M. Bönisch, S. Scudino, M. Calin, L. Schults, J. Eckert, A. Gebert. Powder Technol. 253, 166 (2014). DOI: 10.1016/j.powtec.2013.11.002

13. L.I. Mirkin. Handbook of X-ray diffraction analysis of polycrystals. Fizmathlit, Moscow (1966) 862 p. (in Russian)

14. T.F. Grigor'eva, A.P. Barinova, N.Z. Lyakhov. Mechanochemical synthesis in metal systems. Parallel, Novosibirsk (2008) 309 p. (in Russian)

15. M. Bönisch, M. Calin, L. Giebeler, A. Helth, A. Gebert, W. Skrotzki, J. Eckert. J. Appl. Cryst. 47, 1374 (2014). DOI: $10.1107 /$ S1600576714012576

16. V. D. Cojocaru, D. Raducanu, T. Gloriant, I. Cinca. JOM. 64(5), 573 (2012). DOI: 10.1007/s11837-012-0312-6

17. B. Predel. Nb-Ti (Niobium-Titanium). Vol. 5H in Phase Equilibria, Crystallographic and Thermodynamic Data of Binary Alloys'. Heidelberg, Berlin, Springer, LandoltBörnstein p. 1 - 3. DOI: 10.1007/10522884_2202

18. M. Bönisch, A. Panigrahi, M. Calin, T. Waitz, M. Zehetbauer, W. Skrotzki, J. Eckert. J. of Alloys and Compounds 697, 300 (2017). DOI: $10.1016 /$ j.jallcom.2016.12.108

19. M. Bönisch, M. Calin, T. Waitz, A. Panigrahi, M. Zehetbauer, A. Gebert, W. Skrotzki, J. Eckert. Sci. Technol. Adv. Mater. 14, 055004 (2013). DOI: $10.1088 / 1468-6996 / 14 / 5 / 055004$ 